\title{
DIVERSIDAD GENÉTICA EN RESTOS HUMANOS DE CONTEXTOS ARQUEOLÓGICOS TARDÍOS DE LA PROVINCIA DE SANTIAGO DEL ESTERO A PARTIR DEL ESTUDIO DE ADN MITOCONDRIAL
}

\author{
MITOCHONDRIAL DIVERSITY OF HUMAN REMAINS FROM THE LATE \\ PRE-HISPANIC PERIOD IN THE PROVINCE OF SANTIAGO DEL ESTERO, \\ ARGENTINA
}

\author{
María Pía Tavella', Darío A. Demarchi', Rodrigo Nores* \\ ${ }^{I}$ Instituto de Antropología de Córdoba (CONICET-UNC). Facultad de Filosofía y Humanidades. Universidad Nacional de Córdoba \\ (UNC). Córdoba. Argentina
}

PALABRAS CLAVE: linajes maternos; paleogenética; filogeografía; centro de Argentina

RESUMEN En este artículo se presentan los primeros resultados del secuenciamiento de la Región Hipervariable I del ADN mitocondrial de restos óseos humanos arqueológicos de la provincia de Santiago del Estero, con el objeto de contribuir al conocimiento sobre la diversidad genética de las poblaciones de la llanura santiagueña y los procesos de interacción con grupos de otras regiones de Argentina en tiempos prehispánicos tardíos. Se obtuvieron resultados positivos en 5 de las 10 muestras estudiadas que permitieron la identificación de 5 haplotipos diferentes. Una de las muestras, proveniente del norte del Río Dulce, presenta las mutaciones características del subhaplogrupo D1j, mientras que los demás individuos fueron asignados a linajes derivados de $\mathrm{C} 1$. La comparación de los haplotipos obtenidos en este trabajo con secuencias prehispánicas compiladas de la literatura no muestra una conexión con las poblaciones que habitaron el NOA en tiempos tardíos ni tampoco con los grupos chaco-litoraleños. En cambio, se observa claramente un vínculo biológico entre las poblaciones de la llanura santiagueña y los grupos de la región central de Argentina (fundamentalmente de la actual provincia de Córdoba) y de los valles del centro-oeste argentino. A pesar de su reducido número, los haplotipos obtenidos dan cuenta de este fenómeno: de las cinco secuencias obtenidas, tres fueron asignadas a los linajes $\mathrm{D} 1 \mathrm{j}, \mathrm{C} 1 \mathrm{~d} 1 \mathrm{~b}$ y $\mathrm{C} 1 \mathrm{~b}+146$ que han sido señalados como indicadores de un estrecho vínculo entre las poblaciones del centro y el oeste argentino, y evidencia del mantenimiento de flujo génico entre ellas. Rev Arg Antrop Biol 22(1), 2020. doi:10.24215/18536387e013

KEYWORDS maternal lineages; paleogenetics; phylogeography; central Argentina

ABSTRACT In this article we present the first set of mitochondrial hypervariable region I sequences from human archaeological remains from the province of Santiago del Estero, with the aim of contributing to the knowledge of the genetic diversity of the populations of the Santiago plains and the processes of interaction with groups from other regions of Argentina in late pre-Hispanic times. Positive results were obtained in 5 out of the 10 analyzed samples, which allowed the identification of 5 different haplotypes. One of the samples, from the north of the Dulce river, shows the characteristic mutations of subhaplogroup $\mathrm{D} 1 \mathrm{j}$, while the other individuals were assigned to derived lineages of $\mathrm{C} 1$. The comparison of the haplotypes obtained in this work with pre-Hispanic sequences compiled from the literature did not

La provincia de Santiago del Estero ocupa la parte más árida del sector septentrional de la llanura Chaco-Pampeana. Su clima es subtropical, con escasas lluvias estivales cuyas aguas se evaporan o filtran en charcos y pantanos ante la falta de declive. El territorio santiagueño es atravesado por dos grandes cursos de agua de régimen torrencial, los ríos Dulce y Salado, que nacen en los cordones montañosos de Salta y show a genetic connection with the populations that inhabited northwest Argentina region in the Late Period nor with the Chaco-Littoral groups. Nevertheless, a biological link was clearly observed between the populations of the Santiago del Estero plains and the groups of the central region of Argentina (mainly of the province of Córdoba), and of the valleys of the center-west of Argentina. Despite the small sample size, the detected haplotypes demonstrate these linkages: three out of the five sequences obtained were assigned to the lineages $\mathrm{D} 1 \mathrm{j}, \mathrm{C} 1 \mathrm{~d} 1 \mathrm{~b}$ and $\mathrm{C} 1 \mathrm{~b}+146$ that have been pointed out as indicators of close genetic relationships between the populations from Central and Western Argentina, as well as evidence of sustained gene flow between them. Rev Arg Antrop Biol 22(1), 2020. doi:10.24215/18536387e 013

Financiamiento: SECyT (UNC) 2016, ANPCyT (PICT 2013, No 1715; PICT 2015, No 3155) y CONICET (PIP 2015-2017, 1122015-0100953-CO; PUE 2016 IDACOR)

*Correspondencia a: Rodrigo Nores. Museo de Antropología. Av. Hipólito Yrigoyen 174. 5000 Córdoba. Argentina. E-mail: rodrigonores@ffyh.unc.edu.ar

Recibido 24 Enero 2019; aceptado 29 Abril 2019

doi:10.24215/18536387e013 
Catamarca y cruzan la provincia en sentido noroeste a sudeste. El río Dulce desemboca en la laguna Mar Chiquita, en la provincia de Córdoba, en tanto que el río Salado finaliza su curso en el río Paraná, en la provincia de Santa Fe (Fig. 1). Para las poblaciones humanas, la ocupación del terreno siempre ha estado determinada por la necesidad imprescindible de agua de alcance fácil y disponibilidad permanente. En Santiago del Estero, estas rutas obligatorias fueron trazadas por los cursos fluviales y depresiones, habilitadas especialmente durante la estación de lluvias. En este sentido, los ríos Dulce y Salado han constituido, desde tiempos inmemoriales, una importante ruta de comunicación entre las sociedades valliserranas del noroeste argentino y aquellas de las planicies hacia el sur y el oriente (Drube, 2009).

Las fechas de las primeras ocupaciones de esta región no son certeras, dada la esporádica presencia de sitios precerámicos con tecnología lítica, localizados mayormente en las serranías al sur del territorio provincial (Gómez, 1975; Gramajo de Martínez Moreno, 1992; Togo, 2004), para los cuales tampoco se cuenta con fechados radiocarbónicos. Para el siglo IV, la información se hace más palpable a partir de la identificación de los primeros asentamientos de

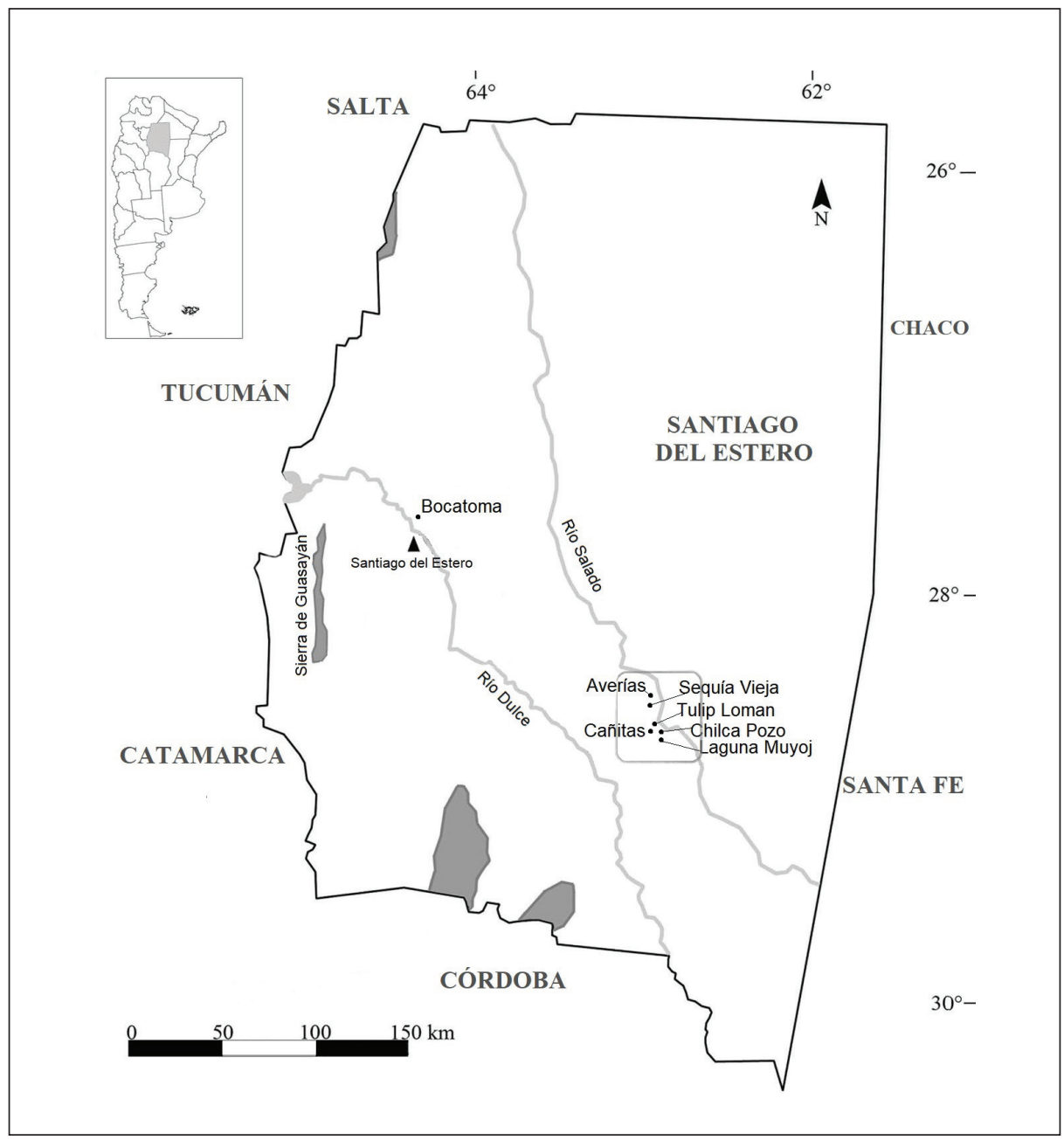

Fig. 1. Mapa de Santiago del Estero con la ubicación aproximada de los sitios arqueológicos de procedencia de las muestras estudiadas. El recuadro marca el área de los Bañados de Añatuya. 
grupos sedentarios dentro de la provincia, que se describen en mayor profundidad a continuación.

Históricamente, la Arqueología organizó la evidencia sobre los desarrollos culturales en el territorio santiagueño en una secuencia cronológica que reconocía dos grandes "Tradiciones", subdivididas a su vez en "Fases". Si bien esta aproximación al registro arqueológico resulta tipologista y homogeneizante, constituye a los fines de este trabajo una herramienta para contextualizar las muestras analizadas. La primera de estas Tradiciones arqueológicas, llamada "Cultura Las Mercedes" (Gómez, 1966), está integrada por un complejo agroalfarero proveniente del NOA, considerado el más antiguo del territorio santiagueño. Por los fechados que se disponen, Las Mercedes se habría desarrollado entre el 350 y el 1100/1200 d.C. (Del Papa, 2012). Hacia el 800 d.C., Las Mercedes se introduce a la llanura y toma contacto con grupos sedentarios locales, transmitiéndoles algunos de sus elementos de ideología Aguada. Es en este momento que se perfilan claramente los rasgos culturales característicos de la denominada "Tradición Cultural Chaco-Santiagueña" (Lorandi, 1978), ubicada en toda la cuenca de los ríos Dulce y Salado, la Mesopotamia entre ambas, y una considerable zona aún no definida al este y oeste de ambos ríos.

A pesar de la uniformidad reportada en la cultura material de las poblaciones santiagueñas tardías, se observa la coexistencia, entre los años 1200 y 1600 d.C., de dos principales tradiciones estilísticas según la decoración de la alfarería, las cuales podrían haber tenido orígenes geográficos diferentes (Lorandi, 1974). Una de ellas, llamada Sunchituyoj, es una expresión estilística de desarrollo local previo, con escasa dispersión fuera del territorio. Entre los años 1200 y 1400 d.C., aparecen en el registro evidencias de contacto constante entre los portadores de esta cerámica y los de la otra tradición característica de la Arqueología santiagueña, denominada Averías. La secuencia cronológica continúa con un momento posterior (entre 1420 y 1610 d.C.), marcado por la integración de estas dos grandes tradiciones alfareras a través del pasaje de rasgos de una a otra. Correlacionando estilos cerámicos y grupos étnicos, la hipótesis planteada por Lorandi (2015) es que dos grupos, al menos, pudieron compartir el mismo territorio y un gran número de asenta- mientos en Santiago del Estero, conformando aldeas biétnicas con alto grado de integración.

Hacia el final del período prehispánico, se observa la expansión de la cerámica Averías por fuera de Santiago, tanto en áreas aledañas (norte de Córdoba, este de Catamarca y Tucumán), como aún más lejos, hacia la zona de Andalgalá, Campo del Arenal, Valle del Cajón, Valle de Santa María y el norte de La Rioja, muy posiblemente debido al traslado de habitantes de la llanura santiagueña como mitimaes al servicio de los incas (Lorandi, 1980). Para esta última etapa, cercana a la llegada de los conquistadores, algunos autores han señalado la vinculación de la cerámica Averías con un aumento de la densidad poblacional y una intensificación de la producción agrícola y la actividad textil, en contraste con los registros que hay para asociaciones con otros tipos de cerámica (Taboada y Angiorama, 2010). En este contexto, los Bañados de Añatuya (Departamento Avellaneda) se configuraron como el sector de mayor desarrollo y relevancia del río Salado medio (Fig. 1).

Los grupos humanos asentados en los Bañados de Añatuya, asociados inicialmente al nombre de juríes y posteriormente denominados tonocotés por las crónicas coloniales, mantuvieron redes de relaciones con poblaciones de los valles intermontanos, los incas y los pueblos chaco-litoraleños al menos desde el año 1200 d.C. hasta tiempos coloniales (Taboada, 2011; TaboadayAngiorama, 2010; Taboada,Angiorama, Leiton y López Campeny, 2013). Estas relaciones se evidencian en el registro arqueológico por la presencia de objetos elaborados con materias primas alóctonas (metales, caracoles del Pacífico, tejidos), asignados al período prehispánico tardío e Inca, y que pueden asociarse con investiduras político-sociales andinas, interpretados como posibles dones y contradones en situación de alianza y reciprocidad (Taboada y Angiorama, 2010). Este tipo de bienes se ha encontrado en abundancia en el sitio Sequía Vieja (470 \pm 50 años $\mathrm{C}^{14} \mathrm{AP}$ ) y en menor medida y variedad en algunos de sus vecinos inmediatos, pero no en el resto de los cerca de 200 sitios conocidos para Santiago. Estas características hacen pensar en los Bañados de Añatuya como un núcleo sociocultural diferenciado de otros sitios más al norte o al este del Salado (Taboada, 2014). Lorandi (1980) plantea que, si bien el Tawantinsuyu no ocupó las tierras 
bajas propiamente dichas, muchos grupos de este origen, parcialmente transculturados a las pautas del altiplano y los valles colindantes, jugaron un rol importante en la defensa de la frontera oriental del imperio inca contra los ataques de los chiriguanos al norte y de los lules al sur. Estas áreas de frontera se habrían integrado al Tawantinsuyu a través de pactos políticos confirmados con alianzas matrimoniales y el intercambio de dones.

Con respecto a la relación entre los grupos sedentarios locales del Salado medio y los pueblos chaco-litoraleños, Lorandi $(1978 ; 1980)$ y Castro Olañeta (2013) acuerdan en considerar que los lules, un grupo originario del Chaco, avanzaron hacia el oeste pocos años antes de la llegada de los españoles, mezclándose con los habitantes locales (tonocotés), sedentarizándose e incorporando nuevas prácticas de acceso y producción de recursos. Hay registros claros y presencia recurrente desde al menos el 1000 d.C. (Lorandi, 1978) de materiales y rasgos que se han asignado a tradiciones alfareras chaqueñas y del litoral, como las campanas y alfarerías gruesas y los apéndices en forma de loros en varios sectores de Santiago del Estero, y una importante cantidad de pipas cerámicas halladas en los sitios de Sequía Vieja y Averías en la zona de los Bañados de Añatuya. Estos elementos han sido interpretados como indicadores de una integración más bien pacífica y quizás bastante generalizada de los aportes poblacionales chaco-litoraleños (Taboada, 2017).

Estudios de deformación craneana en poblaciones agroalfareras de Santiago del Estero observaron la presencia minoritaria de individuos con un patrón deformatorio diferencial. Cráneos femeninos sin deformación, hallados en contextos con cerámica Averías, probablemente corresponderían a etnicidades chaqueñas, quienes no acostumbraban a realizar esa práctica. Por su parte, aquellos cráneos con deformación cuneiforme (del sitio Bocatoma) y tabular erecta planofrontal (provenientes de la región del río Salado medio) podrían constituir evidencias de contacto con poblaciones del área andina, en ese momento bajo dominio incaico, o bien con pueblos de las florestas de tierras bajas ubicadas al este de los Andes (Drube, 2010).

Teniendo en consideración el complejo escenario planteado por las diversas evidencias acerca de las interacciones entre las poblaciones santiagueñas y otros grupos prehispánicos de Argentina, es posible interrogarse si la composición genética de las poblaciones antiguas de Santiago del Estero refleja tales vínculos sociales y movimientos poblacionales con respecto a los habitantes del Noroeste argentino y a los grupos Chaco-Litoraleños. Por otra parte, resulta de interés científico indagar sobre la continuidad de los linajes maternos prehispánicos en la población santiagueña contemporánea, siendo esta última producto de los complejos y sucesivos eventos de mestizaje que caracterizaron la conformación de las poblaciones nacionales latinoamericanas. En ese sentido, el ADN antiguo (ADNa), es decir, aquel material genético que se extrae de restos arqueológicos, puede aportar información sobre los procesos evolutivos de las poblaciones humanas: permite abordar el estudio de eventos migratorios, patrones de residencia y relaciones genéticas entre poblaciones humanas, teniendo en cuenta su dimensión temporal (Hofreiter, Davis, Poinar, Kuch y Pääbo, 2001). Durante la última década se han incrementado los análisis de $\mathrm{ADNa}$ tanto en el actual territorio argentino como en el resto de Sudamérica (ver revisión en Llamas et al., 2016; Postillone, Crespo, Russo y Cardozo, 2014). La mayoría de los estudios genéticos de poblaciones antiguas utilizan marcadores uniparentales, principalmente del ADN mitocondrial (ADNmt) que, por su abundancia en la célula, incrementa las posibilidades de recuperar material genético de restos arqueológicos que han sufrido diferentes procesos que degradan el ADN (Hummel, 2003). Mediante técnicas moleculares se han identificado al menos 16 haplogrupos mitocondriales fundadores que ingresaron al continente americano en distintos momentos y utilizando rutas de poblamiento alternativas (Brandini et al., 2018; Malhi et al., 2010; Perego et al., 2010; Tamm et al., 2007). Dentro de estos haplogrupos, la definición de clados geográficamente restringidos permite inferir procesos de diferenciación local (Bodner et al., 2012; De Saint Pierre et al., 2012a y b; García, Pauro, Nores, Bravi y Demarchi, 2012; Gomez-Carballa et al., 2018; Motti et al., 2017).

En este trabajo se presentan los primeros resultados del secuenciamiento de la Región Hipervariable I del ADN mitocondrial de restos óseos humanos de la provincia de Santiago 
del Estero, con el objeto de contribuir al conocimiento sobre la diversidad genética de las poblaciones nativas de la llanura santiagueña y los procesos de interacción con grupos de otras regiones de Argentina en tiempos tardíos.

\section{MATERIAL Y MÉTODOS}

\section{Muestra}

Se seleccionaron 10 muestras dentarias procedentes de distintos sitios arqueológicos de la provincia de Santiago del Estero (Tabla 1, Fig. 1). Ocho de ellas fueron obtenidas de la colección de restos humanos del Museo de Ciencias Antropológicas y Naturales "Emilio y Duncan Wagner" de la ciudad de Santiago del Estero, entre las cuales 7 provienen de sitios ubicados en los Bañados de Añatuya, en tanto que una no posee datos de procedencia (pero puede presumirse un origen cercano al núcleo del Salado medio donde los hermanos Wagner realizaron sus excavaciones). El contexto arqueológico de los sitios de procedencia sugiere que estas muestras corresponden a la última fase de la secuencia cronológica de Santiago del Estero, entre los 1400 y 1600 d.C. (Fase Oloma Bajada-Icaño, sensu Lorandi, 1974). Finalmente, 2 de las muestras seleccionadas fueron tomadas de la colección Von Hauenschild del Museo de Antropología de Córdoba (atribuibles a las excavaciones efectuadas por éste al norte del Río Dulce), una de ellas originaria del sitio Bocatoma y la otra sin datos de procedencia. No se han realizado dataciones en Bocatoma, no obstante, la cerámica en este sitio adscribe casi en su totalidad al complejo Sunchituyoj, con muy escasa presencia de tiestos Averías en superficie (Drube, 2010; Gómez, 2009).

\section{Análisis de ADN antiguo}

\section{Precauciones para evitar la contaminación}

Diversas precauciones fueron tomadas para minimizar el riesgo de contaminación de las muestras a lo largo de todo el estudio, desde la recolección hasta el trabajo en el laboratorio de extracción y tipificación del ADN. En general, se siguieron las recomendaciones presentadas por Pääbo et al. (2004) y descritas por Nores y Demarchi (2011).

\section{Extracción de ADN}

El procesamiento de las piezas dentales y la extracción de ADN se realizaron por duplicado para cada muestra en el Laboratorio de ADN Antiguo, ubicado en el Centro de Investigación del Patrimonio Arqueológico de Córdoba (CIPAC). Se siguió un protocolo de extracción basado en la descalcificación y digestión de piezas dentarias. En primer término, las muestras fueron sumergidas en hipoclorito de sodio al $6 \%$ durante 5-15 minutos, luego lavadas repetidamente con agua destilada y secadas en estufa. A continuación, fueron pulverizadas con torno dental a baja velocidad. Aproximadamente $0,3 \mathrm{~g}$ de polvo fueron incubados en presencia de $1 \mathrm{ml}$ de una solución de $0,5 \mathrm{M}$ EDTA ( $\mathrm{pH} 8,0)$ y $1 \mathrm{mg}$ de proteinasa $\mathrm{K}$ a $56^{\circ} \mathrm{C}$ con agitación durante toda una noche. Finalmente, se centrifugó a $5000 \mathrm{~g}$ por 5 minutos y se purificó el sobrenadante obtenido usando el kit Wizard SV PCR Clean-Up System (Promega) que se basa en la afinidad del ADN por la sílice en presencia de altas concentraciones salinas. En cada extracción realizada se incorporó un blanco que consiste en un tubo sin muestra sometido al mismo protocolo, y que posteriormente es analizado en paralelo al ADN extraído, a fin de corroborar que no hubo contaminación durante el procedimiento.

\section{Secuenciamiento de la Región Hipervariable I del ADN mitocondrial}

Debido a la fragmentación del ADN en las muestras antiguas, se amplificaron por PCR tres fragmentos solapantes menores a 221 pares de bases (pb) de la Región Hipervariable I (RHV I), entre las posiciones 16023 y 16410 , utilizando los iniciadores: HVR1_P1F y HVR1_P1Rc (Raff et al., 2010), M13-L16120, M13R-H16239 y M13-L16208 (Adachi et al., 2009), y R16410 (Gabriel et al., 2001) (Tabla 2). A fin de refinar la caracterización de los subhaplogrupos de $\mathrm{C} 1$, se secuenció un fragmento de $284 \mathrm{pb}$ perteneciente a la Región Hipervariable II (RHV II), en busca del polimorfismo 493G, diagnóstico de C1b, utilizando los iniciadores F314 y R597 (Motti, 2012) (Tabla 2). Las reacciones de PCR se 1levaron a cabo en un volumen total de $55 \mu \mathrm{l}$ conteniendo 1X de GoTaq Buffer (Promega), 0,20mM de cada dNTP (Promega), 0,28 $\mu \mathrm{M}$ de cada iniciador, 2,75U de GoTaq DNA Polymerase (Promega), $0,1 \mathrm{mg} / \mathrm{ml}$ de BSA y 5-6 $\mu 1$ de la muestra 
TABLA 1. Muestras analizadas y resultados obtenidos

\begin{tabular}{|c|c|c|c|c|c|}
\hline & \multirow[b]{2}{*}{ Muestra } & \multicolumn{4}{|c|}{ Polimorfismos } \\
\hline & & Procedencia & RHV I (16023-16410) (+16000) & $\begin{array}{l}\text { RHV II (128-256 } \\
\quad \text { y 368-585) }\end{array}$ & Linaje \\
\hline \multirow{8}{*}{$\begin{array}{l}\text { Colección } \\
\text { Wagner } \\
\text { (región del } \\
\text { Salado medio) }\end{array}$} & 9SE & $\begin{array}{l}\text { Laguna } \\
\text { Muyoj }\end{array}$ & $223 \mathrm{~T} 298 \mathrm{C} 325 \mathrm{C} 327 \mathrm{~T}$ & - & $\mathrm{C} 1$ \\
\hline & $11 \mathrm{SE}$ & Averías & n.d. & - & n.d. \\
\hline & $12 \mathrm{SE}$ & $\begin{array}{l}\text { Chilca } \\
\text { Pozo }\end{array}$ & n.d. & - & n.d. \\
\hline & $16 \mathrm{SE}$ & $\begin{array}{l}\text { Laguna } \\
\text { Muyoj }\end{array}$ & $223 \mathrm{~T} 298 \mathrm{C} 325 \mathrm{C} 327 \mathrm{~T} 344 \mathrm{~T}$ & $\begin{array}{c}146 \mathrm{C} 249 \mathrm{~d} \\
489 \mathrm{C} 493 \mathrm{G} 523 \mathrm{~d} \\
524 \mathrm{~d}\end{array}$ & $\mathrm{C} 1 \mathrm{~b}$ \\
\hline & 22SE & $\begin{array}{l}\text { Sequía } \\
\text { Vieja }\end{array}$ & n.d. & - & n.d. \\
\hline & $27 \mathrm{SE}$ & $\begin{array}{l}\text { Tulip } \\
\text { Loman }\end{array}$ & $223 \mathrm{~T} 325 \mathrm{C} 327 \mathrm{~T}$ & $\begin{array}{l}\text { 489C 493G 523d } \\
524 d\end{array}$ & $\mathrm{C} 1 \mathrm{~b}$ \\
\hline & $34 \mathrm{SE}$ & Cañitas & n.d. & - & n.d. \\
\hline & 46SE & $\begin{array}{l}\text { Sin } \\
\text { procedencia }\end{array}$ & $\begin{array}{l}\text { 051G 223T 259T 271C 298C 311C } \\
\text { 325C 327T }\end{array}$ & - & Cldlb \\
\hline $\begin{array}{l}\text { Colección } \\
\text { Von }\end{array}$ & $47 \mathrm{SE}$ & $\begin{array}{l}\text { Sin } \\
\text { procedencia }\end{array}$ & n.d. & - & n.d. \\
\hline $\begin{array}{l}\text { Hauenschild } \\
\text { (Norte del } \\
\text { Río Dulce) }\end{array}$ & $54 \mathrm{SE}$ & Bocatoma & $223 \mathrm{~T} 242 \mathrm{~T} 311 \mathrm{C} 325 \mathrm{C} 362 \mathrm{C}$ & - & D1j \\
\hline
\end{tabular}

n.d.:no determinado.

TABLA 2. Información y referencia bibliográfica de los iniciadores utilizados

\begin{tabular}{|c|c|c|c|c|}
\hline Nombre & Posición & Secuencia & $\begin{array}{l}\text { Largo del } \\
\text { amplicón } \\
\text { generado }\end{array}$ & $\begin{array}{c}\text { Referencia } \\
\text { bibliográfica }\end{array}$ \\
\hline HVR1_P1F & $16023-16043$ & 5' GTTCTTTCATGGGGAAGCAG 3' & \multirow{2}{*}{$160 \mathrm{pb}$} & \multirow{2}{*}{$\begin{array}{c}\text { Raff } \\
\text { et al., } 2010\end{array}$} \\
\hline HVR1_P1Rc & $16182-16160$ & 5' TTGATGTGGATTGGGTTTTT 3' & & \\
\hline M13-L16120 & $16120-16139$ & 5' TTACTGCCAGCCACCATGAA 3' & \multirow{2}{*}{$118 \mathrm{pb}$} & \multirow{2}{*}{$\begin{array}{c}\text { Adachi } \\
\text { et al., } 2009\end{array}$} \\
\hline M13R-H16239 & $16220-16239$ & 5' TGGCTTTGGAGTTGCAGTTG 3' & & \\
\hline M13-L16208 & $16209-16227$ & 5' CCCCATGCTTACAAGCAAG 3' & \multirow{2}{*}{$165 \mathrm{pb}$} & \multirow{2}{*}{$\begin{array}{c}\text { Gabriel } \\
\text { et al., } 2001\end{array}$} \\
\hline R16410 & $16391-16410$ & 5' GAGGATGGTGGTCAAGGGAC 3' & & \\
\hline F314 & $314-333$ & 5' CCGCTTCTGGCCACAGCACT 3' & \multirow{2}{*}{$284 \mathrm{pb}$} & \multirow{2}{*}{ Motti, 2012} \\
\hline R597 & $576-597$ & 5' GAGGAGGTAAGCTACATAAACT 3' & & \\
\hline
\end{tabular}

de ADNa. En las reacciones de amplificación se incluyeron controles positivos y negativos. Las condiciones de ciclado fueron: un ciclo inicial de desnaturalización durante 6 minutos a $94^{\circ} \mathrm{C}$; 50 ciclos de desnaturalización por 30 segundos a $94^{\circ} \mathrm{C}$, hibridación por 45 segundos a $53^{\circ} \mathrm{C}$ y 
elongación por 45 segundos a $72^{\circ} \mathrm{C}$; y un ciclo de elongación final de 5 minutos a $72^{\circ} \mathrm{C}$. Los productos de PCR se enviaron a Macrogen (Seúl, Corea) para su purificación y secuenciamiento de ambas cadenas de ADN. Las secuencias obtenidas fueron corregidas manualmente y alineadas con la Secuencia de Referencia revisada de Cambridge (rCRS) (Andrews et al., 1999), usando el programa Sequencher versión 5.3 (Gene Codes Corporation). Posteriormente, fueron asignadas a los subhaplogrupos correspondientes utilizando el programa HaploGrep 2 (Kloss-Brandstaetter et al., 2011), que se basa en la base de datos Phylotree (van Oven, 2015), y mediante búsqueda bibliográfica.

\section{Comparación de los haplotipos obtenidos}

Se contrastaron los haplotipos determinados en la muestra prehispánica de Santiago del Estero con una base de datos de secuencias de la RHV I de poblaciones prehispánicas sudamericanas (Fehren-Schmitz et al., 2015; Figueiro et al., 2017; Gómez-Carballa et al., 2015; Llamas et al., 2016; Nores, Fabra, García y Demarchi, 2017; Postillone et al., 2017; Russo, Gheggi, Avena, Dejean y Cremonte, 2017 y referencias allí citadas), con el objeto de indagar sobre las interacciones entre las poblaciones santiagueñas y otros grupos prehispánicos. Además, se extendió la búsqueda a poblaciones contemporáneas del Cono Sur (Bobillo et al., 2010; Cabana, Merriwether, Hunley y Demarchi, 2006; Cardoso et al., 2013; Catelli et al., 2011; Figueiro, Hidalgo y Sans, 2011; García, Pauro, Bailliet, Bravi y Demarchi, 2018; Gómez-Carballa et al., 2018; Motti, 2012; Salas, Jaime, Álvarez-Iglesias y Carracedo, 2008; Sevini et al., 2013). Esta selección no pretende ser una síntesis completa de los estudios publicados de ADN mitocondrial en Sudamérica, sino servir como marco para estudiar a la población de Santiago del Estero en un ámbito geográfico mayor, incluyendo poblaciones que constituyan puntos de comparación coherentes con las hipótesis planteadas. Se construyó un mapa de isofrecuencias de la distribución actual de uno de los linajes de la muestra arqueológica discutidos en el texto, mediante el algoritmo de Kriging utilizado en el programa Surfer 10 (Golden Software 2002). Para ello se tuvieron en cuenta sólo los trabajos que presentaran frecuencias de la población total analizada.
Por otra parte, se compararon las secuencias obtenidas en este estudio con las reportadas para la población contemporánea de la provincia de Santiago del Estero (Catelli et al., 2011; Pauro, García, Nores y Demarchi, 2013) con el fin de rastrear la continuidad de los linajes mitocondriales prehispánicos en este territorio.

\section{RESULTADOS}

Las precauciones tomadas durante el procesamiento y análisis de las muestras en el laboratorio fueron exitosas, ya que no se observaron productos de amplificación en los controles negativos de PCR y blancos de extracción. Se obtuvieron secuencias confiables de la RHV I en cinco de las diez muestras procesadas, mientras que en las restantes no se obtuvieron amplificaciones o fueron espurias.

La región secuenciada (16023-16410 pb) permitió la identificación de haplotipos diferentes en las cinco muestras (Tabla 1). La muestra 54SE, proveniente del norte del Río Dulce, presenta las mutaciones $16242 \mathrm{~T}$ y $16311 \mathrm{C}$, características del subhaplogrupo $\mathrm{D} 1 \mathrm{j}$. Los demás individuos fueron asignados al haplogrupo $\mathrm{C} 1$. La presencia del polimorfismo $16051 \mathrm{G}$ en la secuencia del individuo 46SE indica su pertenencia al subhaplogrupo $\mathrm{C} 1 \mathrm{~d}$, mientras que la mutación $493 \mathrm{G}$ observada en las secuencias de 16SE y 27SE permitió asignarlas a C1b. La primera de ellas exhibe, a su vez, una transición en la posición 16344; en tanto que la segunda, la reversión de la mutación $16298 \mathrm{C}$, esperada para los linajes derivados de M8. Esta reversión se puede observar en paralelo en varias secuencias $\mathrm{C} 1 \mathrm{~b}$, tanto antiguas como contemporáneas, con diversos orígenes geográficos y con polimorfismos diferentes en la RVH II (Bobillo et al., 2010; Kemp, Tung y Summar, 2009; Rieux et al., 2014; Tito, Polo y Lewis Jr, 2012). Por esta razón, la lectura realizada en el rango 368-585 de la RHV II no es lo suficientemente informativa como para inferir el vínculo filogenético entre la secuencia de 27SE y alguno de los individuos C1b+@16298 de la literatura.

Por último, la muestra 9SE sólo pudo ser secuenciada dentro del rango de lectura analizado para la RHV I, por lo que su tipificación quedó limitada al haplogrupo $\mathrm{C} 1$. Esto podría deberse al estado de conservación de la mues- 
tra, considerando que el fragmento de la RHV II seleccionado (284 pb) tiene un tamaño mayor al recomendado para análisis de $\mathrm{ADN}$ antiguo.

Al realizar una búsqueda en la literatura de secuencias que presentaran el haplotipo observado en el individuo $16 \mathrm{SE}$, se observó que todas las muestras contemporáneas $\mathrm{C} 1 \mathrm{~b}+16344$ de Argentina se agrupan en un único linaje, caracterizado a su vez por las mutaciones $16519 \mathrm{C}$ de la RHV I (aunque cae fuera del rango de lectura del presente trabajo) y $146 \mathrm{C}$ de la RHV II. El secuenciamiento de un fragmento de $128 \mathrm{pb}$ entre las posiciones 128 y 256 , utilizando los iniciadores M13-L127 y M13R-H257 (Adachi et al., 2009) permitió confirmar la pertenencia de la muestra $16 \mathrm{SE}$ a este linaje $\mathrm{C} 1 \mathrm{~b}+146$.

Por otro lado, en la secuencia de 46SE se observa, además del polimorfismo $16051 \mathrm{G}$, la coocurrencia de tres mutaciones en la RHV I (16259T 16271C 16311C), idénticas a las detectadas en un individuo kolla de Salta cuyo mitogenoma fue adscripto al clado C1d1b por Perego y colaboradores (2010). Por esta razón, si bien no se cuenta con la secuencia mitocondrial completa de 46SE, se asume su pertenencia a este linaje, definido por los polimorfismos $195 \mathrm{C}$ y $928 \mathrm{G}$ (Fig. 2).

Con respecto a la comparación de los haplotipos obtenidos en la muestra de Santiago del Estero con las secuencias prehispánicas compiladas, se destaca que las únicas coincidencias encontradas, a excepción del haplotipo nodal C1 de 9SE, de amplia distribución en América, fueron con individuos de la región central de Argentina (provincia de Córdoba). El linaje D1j de 54SE fue observado también en dos individuos de 4525 \pm 20 (UCI AMS 22288) y $1192 \pm 40$ (MTC 13247) años AP de las costas de la Laguna Mar Chiquita, provincia de Córdoba (García et al., 2012; Nores et al., 2017). Por su parte, el haplotipo C1d1b+16259 16271 16311 de 46SE sólo es compartido con la secuencia de un individuo de $2331 \pm 46$ años $C^{14}$ AP (AA93745) del sitio El Diquecito, ubicado en esa misma región. Este hecho resulta particularmente significativo, teniendo en cuenta que la base de datos de comparación está constituida por 496 secuencias antiguas, de las cuales sólo 31 pertenecen a restos arqueológicos de Córdoba. Por su parte, no se observaron los haplotipos de 16SE y $27 \mathrm{SE}$ en otras muestras arqueológicas.

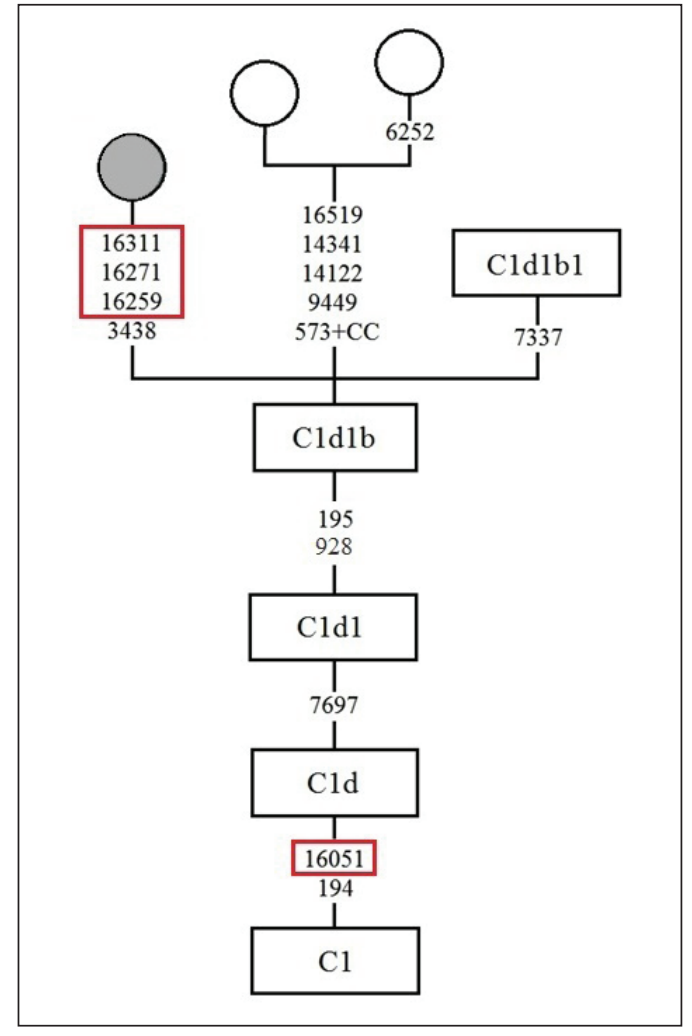

Fig. 2. Sección del árbol filogenético de $\mathrm{C} 1$, modificado de Perego et al. (2010). El círculo gris representa la muestra de un individuo kolla de Salta. Los recuadros rojos señalan las mutaciones identificadas en la secuencia del individuo 46SE de Santiago del Estero que permiten asumir su pertenencia al linaje C1dlb.

\section{DISCUSIÓN}

La muestra arqueológica de Santiago del Estero analizada en este trabajo presenta varios linajes característicos de las poblaciones contemporáneas del centro de Argentina. De acuerdo con Motti (2012), la evidencia a nivel mitocondrial en poblaciones actuales permite postular la existencia de un núcleo de diferenciación poblacional en la región central de Argentina, desde los primeros momentos de ocupación, y un vínculo por origen común y/o extenso flujo génico entre grupos del centro (Córdoba y Santiago del Estero) y el oeste argentino (Catamarca, La Rioja y los valles cuyanos). El caso mejor caracterizado es el del subhaplogrupo D1j (Bodner et al., 2012), al cual pertenece la muestra 54SE del sitio Bocatoma, ubicado al norte del Río Dulce. 
Actualmente, la mayor incidencia de D1j se encuentra en la ciudad de La Rioja (45\%), seguido de Santiago del Estero (28\%), Chepes (27\%), y las provincias de Catamarca (22\%) y Córdoba (18\%) (Motti, 2012; Pauro, 2015). Considerando su patrón de distribución geográfica, con mayor frecuencia y variabilidad en las Sierras Pampeanas, se ha postulado un origen local para este linaje, en el seno de una metapoblación de gran profundidad temporal, que habría ocupado esta región al menos desde hace 4525 años (García et al., 2012). Si bien también se han reportado secuencias D1j en individuos del Golfo San Matías, Río Negro, datados en 3100 y 2200-2300 años AP, se ha hipotetizado que este linaje podría haber arribado al norte de la Patagonia portado por grupos que siguieron una ruta interna a través del centro de Argentina (Crespo, Favier Dubois, Russo, Lanata y Dejean, 2017).

Otro de los linajes característicos del núcleo de diferenciación poblacional constituido por las regiones del centro y oeste de Argentina es $\mathrm{C} 1 \mathrm{~d} 1 \mathrm{~b}$ (Motti et al., 2017), al cual fue adscripto el haplotipo de la muestra 46SE de este estudio. Por su distribución geográfica y edad estimada, Perego y colaboradores (2010) asumen un origen sudamericano para este linaje, durante un estadio intermedio de la diferenciación in situ de los grupos nativo-americanos locales. En Argentina, C1d1b presenta una distribución continua con foco en la región central, alcanzando una frecuencia máxima del $19,5 \%$ en Santiago del Estero, seguido por los wichí de Formosa (9\%), la localidad de Santa María en Catamarca (8\%) y las provincias de Córdoba (7\%) y San Juan (6,6\%), para luego disminuir gradualmente su frecuencia hacia el norte y el sur (García et al., 2018; Pauro, 2015). Por su parte, el motivo derivado $\mathrm{C} 1 \mathrm{~d} 1 \mathrm{~b}+16259$ 16271 16311, observado en la muestra 46SE, ha sido reportado en poblaciones contemporáneas del NOA (Motti 2012; Perego et al., 2010), en Montevideo (Figueiro et al., 2011), en el Gran Chaco (Cabana et al., 2006; Sevini et al., 2013) y en el centro de Argentina (García et al., 2018). A partir de datos poblacionales, se construyó un mapa de isofrecuencias para representar la distribución actual de este linaje, indicando además la localización de los sitios arqueológicos donde fue identificado (Fig. 3). Su mayor frecuencia se encuentra actualmente en la región del Gran Chaco, alcanzando el 4,5\% entre los wichí de Formosa y el 7\% en la población de "criollos" de Misión Nueva Pompeya, provincia de Chaco, aunque está ausente entre los wichí de la misma localidad (Sevini et al., 2013). En el sur de Santiago del Estero, la frecuencia de este haplotipo es del 2,5\% (Pauro et al., 2013) en tanto que, en la provincia de Córdoba, es del 1,2\% (García et al., 2018).

Sin embargo, la antigüedad de la muestra arqueológica cordobesa portadora del motivo C1d1b+1625916271 16311, datada en 2331 \pm 46 años $\mathrm{C}^{14} \mathrm{AP}$, puede interpretarse como evidencia de un origen local de este haplotipo derivado en el centro de Argentina. Bajo este escenario, la presencia de $\mathrm{C} 1 \mathrm{~d} 1 \mathrm{~b}+162591627116311$ observada actualmente en el Gran Chaco se debería a eventos migratorios post-contacto. Sevini y colaboradores (2013) realizaron un exhaustivo muestreo de la localidad chaqueña Misión Nueva Pompeya, observando evidencias de orígenes diferentes de los linajes mitocondriales nativos $\mathrm{y}$ de bajo flujo génico entre los habitantes que autoadscriben como wichí y los que se reconocen como "criollos". Según estos autores, los criollos de Chaco descienden de familias provenientes de Salta y Santiago del Estero que, entre los siglos XIX y XX, se trasladaron al bosque chaqueño junto con su ganado. La alta frecuencia de este linaje observada en este grupo podría explicarse por efecto fundador o por acción de la deriva génica en una población de pequeño tamaño. Por otro lado, evidencias etnohistóricas extienden los movimientos poblacionales entre Santiago del Estero y el Gran Chaco hasta varios siglos hacia atrás, identificando el límite entre Salta y Formosa como un "refugio" para los indígenas tonocotés y lules que huyeron de la Gobernación del Tucumán ante la llegada de los primeros conquistadores, donde se habrían establecido y entablado buenas relaciones con grupos indígenas chaqueños (Farberman, 2016). Tales procesos de interacción en tiempos pericontacto darían cuenta de la presencia del linaje C1d1b+1625916271 16311 entre los wichí de Formosa.

El hecho de que los linajes D1j y C1d1b+16259 1627116311 sean compartidos por las poblaciones prehispánicas de Santiago del Estero y del norte de la provincia de Córdoba (Laguna Mar Chiquita), apoya la hipótesis de García y colaboradores (2012), basada en análisis de poblaciones contemporáneas, sobre 


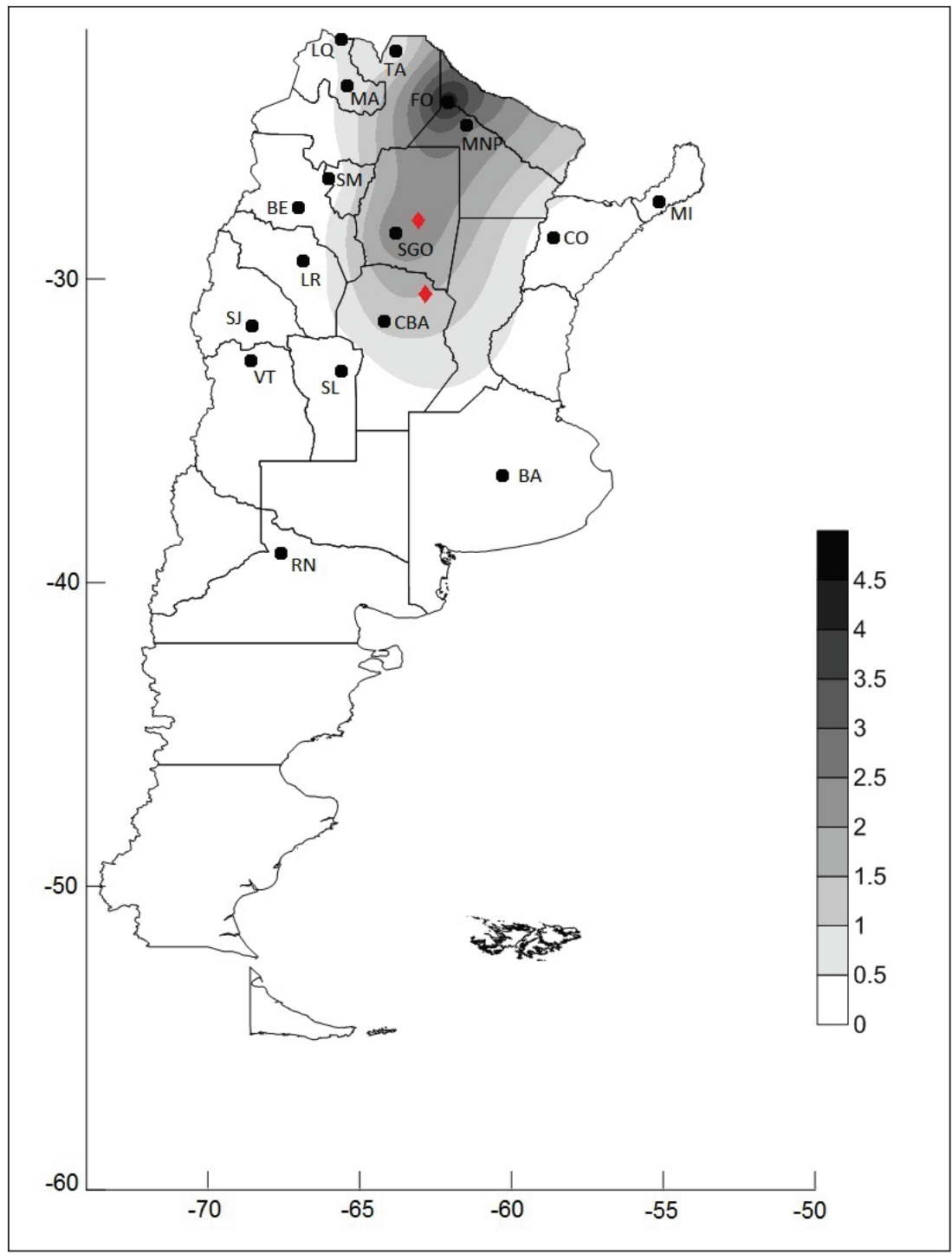

Fig. 3. Mapa de isofrecuencias del linaje C1d1b+16259 1627116311 en poblaciones contemporáneas del cono sur de Sudamérica -con excepción de las secuencias reportadas en Montevideo (Figueiro et al., 2011) y en Salta (Perego et al., 2010), por no presentar frecuencias poblacionales-. LQ: La Quiaca, Jujuy; TA: Tartagal, Salta; MA: Maimará, Jujuy; SM: Santa María, Catamarca; BE: Belén, Catamarca; SJ: Provincia de San Juan; VT: Villa Tulumaya, Mendoza; LR: Provincia de La Rioja (Motti, 2012); CBA: Provincia de Córdoba; SL: Provincia de San Luis (García et al., 2018); SGO: Sur de la provincia de Santiago del Estero (Pauro et al., 2013); FO: Wichí de Formosa (Cabana et al., 2006); MNP: Misión Nueva Pompeya, Chaco (Sevini et al., 2013); MI: Misiones; CO: Corrientes; BA: Buenos Aires; RN: Río Negro (Bobillo et al., 2010). Los rombos rojos indican la procedencia de los individuos arqueológicos que presentan este haplotipo.

una antigua metapoblación que habría habitado el área de las Sierras Pampeanas.

Por su parte, la muestra 16SE fue asignada al linaje $\mathrm{C} 1 \mathrm{~b}+146$. De acuerdo con Motti (2012), a pesar de que la posición 146 es un sitio al- tamente variable, la distribución geográfica que presenta en el territorio argentino permite sustentar la hipótesis de la existencia de un linaje monofilético derivado de $\mathrm{C} 1 \mathrm{~b}$, identificado en la Región Control únicamente por una transición 
en esta posición. Los mitogenomas completos disponibles para Argentina (Salta, Tucumán y Catamarca) pertenecientes al linaje $\mathrm{C} 1 \mathrm{~b}+146$ (Tamm et al., 2007) presentan una transición en la posición 12813, lo cual refuerza la hipótesis de monofilia, que se extiende a las muestras que sólo han sido secuenciadas a nivel de la Región Control. Sin embargo, dado el nivel de resolución disponible para la mayoría de las muestras de Argentina, no es posible afirmar conexiones a nivel extra-regional (Motti, 2012).

A partir del análisis filogeográfico de $\mathrm{C} 1 \mathrm{~b}+146$, Motti (2012) propone un modelo de amplia distribución inicial de un linaje ancestral que luego se habría diferenciado en forma local, con la aparición de linajes derivados que adquirieron mayor frecuencia en determinadas regiones. A pesar de que las mayores frecuencias se concentran en el centro-oeste del territorio argentino, existe gran variedad de haplotipos en la ciudad de Tartagal, Provincia de Salta. Dentro de la muestra poblacional de esa localidad, se reportó un haplotipo derivado de $\mathrm{C} 1 \mathrm{~b}+146$ con la mutación 16344T, la cual está presente en una de las muestras de este trabajo. Al compilar las secuencias de Argentina con el haplotipo C1b+146 16344 y representar sus relaciones filogenéticas, se evidenció un patrón de diferenciación dentro de este sub-linaje que no estaba plasmado en la red filogenética elaborada por Motti (2012). En el esquema construido, se observa un estado ancestral de C1b+146 16519194 16344, representado por una secuencia proveniente de la provincia de Córdoba, a partir del cual derivan dos haplotipos presentes en poblaciones del Gran Chaco, Tartagal y San Salvador de Jujuy (Fig. 4). Considerando el rango de lectura obtenido para la RHV II, no es posible definir la posición de la secuencia de 16SE en este esquema. Para ello, será necesaria la tipificación de los polimorfismos de la Región Control completa.

Retomando las hipótesis planteadas en la introducción con base en la evidencia arqueológica, los resultados producidos hasta el momento mediante el análisis de la Región Control del ADNmt de la muestra arqueológica de Santiago del Estero no permiten establecer fehacientemente una conexión entre estas poblaciones $\mathrm{y}$ aquellas que habitaron el NOA en tiempos tardíos e incaico, ni tampoco con los grupos chaco-litoraleños. En cambio, las secuencias mitocondriales prehispánicas obtenidas reflejan claramente un vínculo biológico entre las poblaciones de la llanura santiagueña y los grupos de la región central de Argentina (fundamentalmente de Córdoba) y de los valles del centrooeste. A pesar de su reducido número, los haplotipos detectados dan cuenta de este fenómeno: de las cinco secuencias mitocondriales antiguas obtenidas, tres fueron asignadas a los linajes D1j, C1d1b y C1b+146 que han sido señalados como indicadores de un estrecho vínculo entre las poblaciones del centro y el oeste argentino, y del mantenimiento de flujo génico entre ellas (Motti, 2012; Motti et al., 2017).

Los resultados presentados en este trabajo se encuentran en línea con evidencias provenientes de otros abordajes de investigación bioantropológica. Estudios craneométricos realizados sobre la colección del Museo de Ciencias Antropológicas y Naturales "Emilio y Duncan Wagner" sugieren afinidad biológica entre las poblaciones tardías de Santiago del Estero y los grupos que habitaban el territorio de las actuales

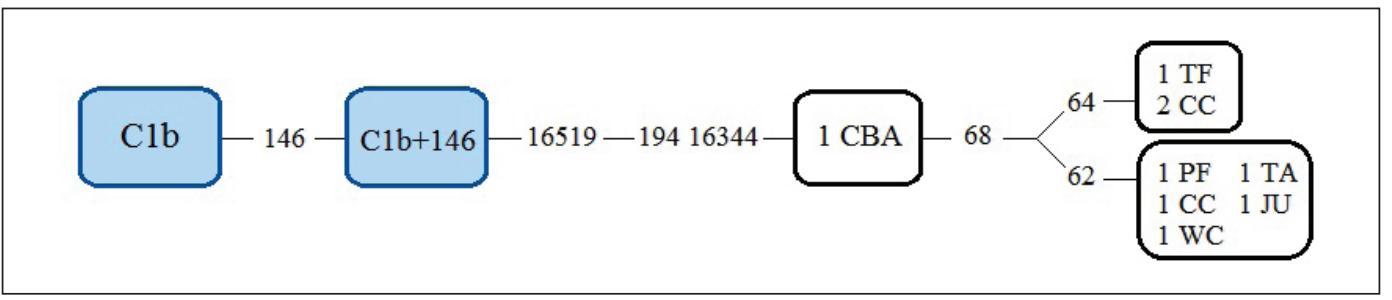

Fig. 4. Esquema filogenético de la diversidad del linaje C1b+146 16344 en Argentina. Los números representan la frecuencia absoluta de cada haplotipo en esa población. CBA: Provincia de Córdoba (García et al., 2018); TF: Toba de Formosa; PF: Pilagá de Formosa (Cabana et al., 2006); CC: Criollos de Chaco; WC: Wichí de Chaco (Sevini et al., 2013); TA: Tartagal, Salta (Motti, 2012); JU: San Salvador de Jujuy (Cardoso et al., 2013). 
provincias de Córdoba, Catamarca, San Juan y Mendoza (Fabra y Demarchi, 2012). Por su parte, Cocilovo y Di Rienzo (1984-1985) encuentran mayor similitud entre las poblaciones de la Región Central (Córdoba y Santiago del Estero) y la de Belén (Catamarca), la cual, a su vez, se asemeja a las de San Juan y Mendoza.

Los estudios genéticos publicados hasta la fecha sobre poblaciones contemporáneas de Santiago del Estero tampoco hallaron evidencia de flujo génico significativo con grupos andinos, en tanto que reportaron varios linajes mitocondriales compartidos con poblaciones de las Sierras Pampeanas (en particular con Córdoba) y del Gran Chaco (Pauro et al., 2013). Teniendo en consideración estos antecedentes, resulta interesante destacar la continuidad de algunos linajes maternos observados en la muestra arqueológica aquí analizada. En la población de las localidades de Sumampa y Villa Atamisqui, ubicadas en el sur de la provincia de Santiago del Estero, los linajes D1j y C1d1b+16259 1627116311 se encuentran presentes en una frecuencia del $13,8 \%$ y del $2,5 \%$, respectivamente (Pauro et al., 2013). Sin embargo, no se ha detectado el haplotipo C1b+146 16344 de la muestra arqueológica 16SE en estas localidades. Esto podría deberse, bien a un error de muestreo, bien a la pérdida de linajes por procesos demográficos del pasado, como la contracción y/o el reemplazo poblacional.

Este trabajo constituye el primer análisis genético de individuos de sitios arqueológicos provenientes del actual territorio de la provincia de Santiago del Estero, lo cual le otorga especial relevancia a la hora de interpretar los patrones de poblamiento y movilidad en la región central de Argentina.

Aunque los resultados son preliminares, evidencian la importancia de los estudios paleogenéticos para contrastar hipótesis acerca de relaciones filogenéticas basadas en la distribución actual de linajes maternos, teniendo en cuenta que esta es producto de sucesivos eventos ocurridos en tiempos prehispánicos, así como durante los procesos de conquista y colonización española, y de construcción del estado-nación argentino. En ese sentido, creemos necesario continuar los análisis del ADNmt a un nivel resolutivo mayor, incrementando además el tamaño muestral y el número de sitios relevados.
Por otro lado, futuros estudios de $\mathrm{ADNa}$ en otras regiones de interés para entender los procesos sociales de las poblaciones prehispánicas tardías de las tierras bajas, tales como el Gran Chaco, podrían aportar valiosa información a la discusión acerca de la existencia de flujo génico con los grupos que habitaron el actual territorio de Santiago del Estero.

\section{AGRADECIMIENTOS}

Deseamos expresar nuestro agradecimiento a las autoridades del Museo de Ciencias Antropológicas y Naturales "Emilio y Duncan Wagner" de la ciudad de Santiago del Estero y a las del Museo de Antropología de Córdoba (UNC), por permitir el análisis de los restos humanos bajo su cuidado.

\section{LITERATURA CITADA}

Adachi, N., Shinoda, K., Umetsu, K., y Matsumura, H. (2009). Mitochondrial DNA analysis of Jomon skeletons from the Funadomari site, Hokkaido, and its implication for the origins of Native American. American Journal of Physical Anthropology, 138(3), 255-265. doi:10.1002/ajpa.20923

Andrews, R. M., Kubacka, I., Chinnery, P. F., Lightowlers, R. N., Turnbull, D. M., y Howell, N. (1999). Reanalysis and revision of the Cambridge reference sequence for human mitochondrial DNA. Nature Genetics, 23(2), 147. doi:10.1038/13779

Bobillo, M. C., Zimmermann, B., Sala, A., Huber, G., Röck, A., Bandelt, H. J., ... Parson, W. (2010). Amerindian mitochondrial DNA haplogroups predominate in the population of Argentina: towards a first nationwide forensic mitochondrial DNA sequence database. International Journal of Legal Medicine, 124(4), 263-268. doi:10.1007/s00414-009-0366-3

Bodner, M., Perego, U. A., Huber, G., Fendt, L., Röck, A. W., Zimmermann, B., ... Parson, W. (2012) Rapid coastal spread of First Americans: Novel insights from South America's Southern Cone mitochondrial genomes. Genome Research, 22(5), 811-820. doi:10.1101/ gr.131722.111

Brandini, S., Bergamaschi, P., Cerna, M. F., Gandini, F., Bastaroli, F., Bertolini, E., ... Torroni, A. (2018). The Paleo-Indian Entry into South America According to mitogenomes. Molecular Biology and Evolution, 35, 299-311. doi:10.1093/molbev/msx267

Cabana, G. S., Merriwether, D. A., Hunley, K., y Demarchi, D. A. (2006). Is the genetic structure of Gran Chaco populations unique? Interregional perspectives on native South American mitochondrial DNA variation. American Journal of Physical Anthropology, 131(1), 108-119. doi:10.1002/ajpa.20410

Cardoso, S., Palencia-Madrid, L., Valverde, L., AlfonsoSánchez, M. A., Gómez-Pérez, L., Alfaro, E., ... de Pancorbo, M. M. (2013). Mitochondrial DNA control region data reveal high prevalence of Native American lineages in Jujuy province, NW Argentina. Fo- 
rensic Science International: Genetics, 7, e52-e55. doi:10.1016/j.fsigen.2013.01.007

Castro Olañeta, I. (2013). Donde estan situados los mas yndios de la jurisdiccion desta ciudad. Surandino Monográfico, 3, 1-23. ISSN 1851-9091

Catelli, M. L., Álvarez-Iglesias, V., Gómez-Carballa, A., Mosquera-Miguel, A., Romanini, C., Borosky, A., ... Salas, A. (2011). The impact of modern migrations on present-day multi-ethnic Argentina as recorded on the mitochondrial DNA genome. BMC Genetics, 12:77. doi:10.1186/1471-2156-12-77

Cocilovo, J. A., y Di Rienzo, J. (1984-1985). Un modelo biológico para el estudio del poblamiento prehispánico del territorio argentino. Correlación fenético-espacial. Relaciones de la Sociedad Argentina de Antropología, 16, 119-135.

Crespo, C. M., Favier Dubois, C., Russo, M. G., Lanata, J. L., y Dejean, C. B. (2017). First analysis of ancient mtDNA genetic diversity in Northern coast of Argentinean Patagonia. Journal of Archaeological Science Reports, 12,91-98. doi:10.1016/j.jasrep.2017.01.011

Del Papa, L. M. (2012). Una aproximación al estudio de los sistemas de subsistencias a través del análisis arqueofaunístico en un sector de la cuenca del Río Dulce y cercanías a la Sierra de Guasayán. Tesis doctoral. Facultad de Ciencias Naturales y Museo, Universidad Nacional de La Plata.

De Saint Pierre, M., Bravi, C. M., Motti, J. M. B., Fuku, N., Tanaka M., Llop, E., ... Moraga, M. (2012a). An alternative model for the early peopling of southern South America revealed by analyses of three mitochondrial DNA haplogroups. PLoS ONE, 7(9), e43486. doi:10.1371/journal.pone.0043486

De Saint Pierre, M., Gandini, F., Perego, U. A., Bodner, M., Gómez-Carballa, A., Corach, D., ... Olivieri, A. (2012b). Arrival of paleo-indians to the southern cone of South America: new clues from mitogenomes. PLoS ONE, 7 (12), e51311. doi:10.1371/journal. pone. 0051311

Drube, H. D. (2009). Las poblaciones aborígenes prehispánicas de Santiago del Estero. Evaluación de sus características bioantropológicas y de sus condiciones de salud, enfermedad y nutrición. Tesis doctoral. Facultad de Ciencias Naturales y Museo, Universidad Nacional de La Plata.

Drube, H. D. (2010). La deformación de cráneo en las sociedades precolombinas de Santiago del Estero. Relaciones de la Sociedad Argentina de Antropología, 35, 69-84.

Fabra, M., y Demarchi, D. A. (2012). Morfología craneofacial y estructura genética en poblaciones del centro de Argentina. Revista Argentina de Antropología Biológica, 14(1), 45-56.

Farberman, J. (2016). La construcción de un espacio de frontera. Santiago del Estero, el Tucumán y el Chaco desde el prehispánico tardío hasta mediados del siglo XVIII. Revista del Museo de Antropología, 9(2), 187198. doi:10.31048/1852.4826.v9.n2.15892

Fehren-Schmitz, L., Llamas, B., Lindauer, S., TomastoCagigao, E., Kuzminsky, S., Rohland, N., ... Haak, W. (2015). A re-appraisal of the early Andean human remains from Lauricocha in Peru. PLoS ONE, 10(6), e0127141. doi:10.1371/journal.pone.0127141

Figueiro, G., Hidalgo, P. C., y Sans, M. (2011). Control Region Variability of Haplogroup C1d and the Tempo of the Peopling of the Americas. PLoS ONE, 6(6), e20978. doi:10.1371/journal.pone.0020978

Figueiro, G., Cabrera Pérez, L., Lindo, J., Mallott, E. K., Owings, A., Malhi, R. S., y Sans, M. (2017). Análisis del genoma mitocondrial de dos individuos inhumados en el sitio arqueológico CG14E01 "Isla Larga" (Rocha,
Uruguay). Revista Argentina de Antropología Biológica, 19(1). doi:10.17139/raab.2017.0019.01.06

Gabriel, M. N., Huffine, E.F., Ryan, J. H., Holland, M. M., y Parsons, T. J. (2001). Improved mtDNA sequence analysis of forensic remains using a "mini-primer set" amplification strategy. Journal of Forensic Science, 46(2), 247-253. doi:10.1520/JFS14957J

García, A., Pauro, M., Nores, R., Bravi, C. M., y Demarchi, D. A. (2012). Phylogeography of mitochondrial haplogroup D1: an early spread of subhaplogroup D1j from Central Argentina. American Journal of Physical Anthropology, 149, 583-590. doi:10.1002/ajpa.22174

García, A., Pauro, M., Bailliet, G., Bravi, C. M., y Demarchi, D. A. (2018). Genetic variation in populations from central Argentina based on mitochondrial and Y chromosome DNA evidence. Journal of Human Genetics, 63, 493-507. doi:10.1038/s10038-017-0406-7

Gómez, R. (1966). La cultura de Las Mercedes (Contribución a su estudio). Ed. Priv. Santiago del Estero.

Gómez, R. (1975). Contribución al conocimiento de las industrias líticas tempranas de Santiago del Estero. Revista del Instituto de Antropología, UNT, 2, 171-187.

Gómez, R. (2009). Arqueología santiagueña: un diseño de investigación para el Formativo Inferior. Fase explorativa. Revista del Museo de Antropología, 2, 53-66.

Gómez-Carballa, A., Catelli, L., Pardo-Seco, J., Martinón-Torres, F., Roewer, L., Vullo, C., y Salas, A. (2015). The complete mitogenome of a 500-year-old Inca child mummy. Science Reports, 5, 16462. doi:10.1038/srep16462

Gómez-Carballa, A., Pardo-Seco, J., Brandini, S., Achilli, A., Perego, U., Coble, M. D., ... Salas, A. (2018). The peopling of South America and the trans-Andean gene flow of the first settlers. Genome Research, 28(6), $767-$ 779. doi: $10.1101 /$ gr. 234674.118

Gramajo de Martínez Moreno, A. J., y Martínez Moreno, H. (1992). "Arqueología de la Subárea Guasayán". Serie Estudio, Museo de Ciencias Antropológicas y Naturales "Emilio y Duncan Wagner" 4, 21-73, Santiago del Estero.

Hofreiter, M., Davis, S., Poinar, H., Kuch, M., y Pääbo, S. (2001). Ancient DNA. Nature Reviews Genetics, 2(5), 353-359. doi:10.1038/35072071

Hummel, S. (2003). Ancient DNA typing. Methods, strategies and applications. Springer-Verlag. Berlin Heidelberg. New York. doi:10.1007/978-3-662-05050-7

Kemp, B. M., Tung, T. A., y Summar, M. L. (2009). Genetic continuity after the collapse of the Wari empire: mitochondrial DNA profiles from Wari and post-Wari populations in the ancient Andes. American Journal of Physical Anthropology, 140(1), 80-91. doi:10.1002/ ajpa. 21037

Kloss-Brandstätter, A., Pacher, D., Schönherr, S., Weissensteiner, H., Binna, R., Specht, G., y Kronenberg, F. (2011). HaploGrep: a fast and reliable algorithm for automatic classification of mitochondrial DNA haplogroups. Human Mutation, 32(1),:25-32. doi: 10.1002/humu.21382.

Lorandi, A. M. (1974). Espacio y tiempo en la prehistoria santiagueña. Relaciones de la Sociedad Argentina de Antropología, 8, 199-236.

Lorandi, A. M. (1978). El Desarrollo Cultural Prehispánico en Santiago del Estero, Argentina. Journal de la Société des Américanistes, 65(1), 63-85. doi:10.3406/ jsa.1978.2156

Lorandi, A. M (1980). La frontera oriental del Tawantinsuyu: El Umasuyu y el Tucumán. Una hipótesis de Trabajo. Relaciones de la Sociedad Argentina de Antropología, 14(1), 147-164.

Lorandi, A. M. (2015). Tukuma - Tukuymanta: los pueblos 
del búho. Santiago del Estero antes de la Conquista. Santiago del Estero: Subsecretaría de la Provincia de Santiago del Estero.

Llamas, B., Fehren-Schmitz, L., Valverde, G., Sounrier, J., Mallick, S., Rohland, N., ... Haak, W. (2016). Ancient mitochondrial DNA provides high resolution time scale of the peopling of the Americas. Science Advances, 2, e1501385. doi:10.1126/sciadv.1501385

Malhi, R. S., Cybulski, J. S., Tito, R. Y., Johnson, J., Harry, H., y Dan, C. (2010). Brief Communication: Mitochondrial Haplotype C4c Confirmed as a Founding Genome in the Americas. American Journal of Physical Anthropology, 141, 494-497. doi:10.1002/ajpa.21238

Motti, J. M. B. (2012). Caracterización de linajes maternos en la población actual del Noroeste y Centro-oeste argentinos. Tesis doctoral. Facultad de Ciencias Naturales y Museo. Universidad Nacional de La Plata.

Motti, J. M. B., Schwab, M. E., Beltramo, J., Jurado-Medina, L. S., Muzzio, M., Ramallo, V., ... Bravi, C. M. (2017). Diferenciación regional de poblaciones nativas de América a partir del análisis de los linajes maternos. Intersecciones en Antropología, 18, 271-282.

Nores, R., y Demarchi, D. A. (2011). Análisis de haplogrupos mitocondriales en restos humanos de sitios arqueológicos de la provincia de Córdoba. Revista Argentina de Antropología Biológica, 13, 43-54.

Nores, R., Fabra, M., García, A., y Demarchi, D. A. (2017). Diversidad genética en restos humanos arqueológicos del sitio El Diquecito (Costa Sur, Laguna Mar Chiquita, Provincia de Córdoba). Revista Argentina de Antropología Biológica, 19(1). doi:10.17139/ raab.2017.0019.01.05

Pääbo, S., Poinar, H., Serre, D., Jaenicke-Despres, V., Hebler, J., Rohland, N., ... Hofreiter, M. (2004). Genetic analyses from ancient DNA. Annual Review of Genetics, 38, 645-679. doi:10.1146/annurev.genet.37.110801.143214

Pauro, M., García, A., Nores, R., y Demarchi, D. A. (2013). Analysis of Uniparental Lineages in Two Villages of Santiago del Estero, Argentina, Seat of Pueblos de Indios in Colonial Times. Human Biology, 85(5): 699 720. doi: $10.3378 / 027.085 .0504$

Pauro, M. (2015). Análisis molecular de linajes uniparentales en poblaciones humanas del centro de Argentina. Tesis doctoral. Facultad de Filosofía y Humanidades, Universidad Nacional de Córdoba.

Perego, U. A., Angerhofer, N., Pala, M., Olivieri, A., Lancioni, H., Hooshiar Kashani, B., ... Torroni, A. (2010). The initial peopling of the Americas: a growing number of founding mitochondrial genomes from Beringia. Genome Research, 20(9), 1174-1179. doi:10.1101/gr.109231.110

Postillone, M. B., Crespo, C. M., Russo, M. G., Cardozo, D. G. (2014). Distribución de haplogrupos mitocondriales amerindios en muestras arqueológicas de Sudamérica. En Castro Esnal, A., Funes, M. L., Grosso, M., Kuperszmit, N., Murgo, A., y Romero, G., (Eds). Entre pasados y presentes IV. Estudios Contemporáneos en Ciencias Antropológicas. Ciudad Autónoma de Buenos Aires: Editorial AINA. p 347-362. doi:10.13140/2.1.5127.3289

Postillone, M. B., Fuchs, M. L., Crespo, C. M., Russo, M. G., Varela, H. H., Carnese, F. R., ... Dejean, C. B. (2017). Linajes maternos en muestras antiguas de la Puna jujeña: comparación con estudios de la región centro-sur andina. Revista Argentina de Antropología Biológica, 19(1) doi:10.17139/raab.19.1.16

Raff, J., Tackney, J., y O'Rourke, D. H. (2010). South from Alaska: a pilot aDNA study of genetic history on the Alaska peninsula and the Eastern Aleutians. Human
Biology, 82(5-6), 677-693. doi:10.3378/027.082.0510

Rieux, A., Eriksson, A., Li, M., Sobkowiak, B., Weinert, L. A., Warmuth, V., ... Balloux, F. (2014). Improved Calibration of the Human Mitochondrial Clock Using Ancient Genomes. Molecular Biology and Evolution, 31, (10), 2780-2792. doi:10.1093/molbev/msu222

Russo, M. G., Gheggi, M. S., Avena, S. A., Dejean, C. B., y Cremonte, M. B. (2017). Linajes mitocondriales en muestras de esquina de Huajra (Jujuy, Argentina). Aportes al estudio de la ocupación incaica en la región y la procedencia de sus habitantes. Revista Argentina de Antropología Biológica, 19(1), 2017. doi:10.17139/ raab.2017.19.1.15

Salas, A., Jaime, J. C., Álvarez-Iglesias, V., y Carracedo, A. (2008). Gender bias in the multiethnic genetic composition of central Argentina. Journal of Human Genetics, 53(7): 662-674. doi: 10.1007/s10038-008-0297-8

Sevini, F., Yao, D. Y., Lomartire, L., Barbieri, A., Vianello, D., Ferri, G., ... Franceschi, Z. A. (2013). Analysis of Population Substructure in Two Sympatric Populations of Gran Chaco, Argentina. PLoS ONE, 8(5): e64054. doi:10.1371/journal.pone.0064054

Taboada, C. (2011). Repensando la Arqueología de Santiago del Estero. Construcción y análisis de una problemática. Relaciones de la Sociedad Argentina de Antropología, $36,197-220$

Taboada, C. (2014). Sequía vieja y los bañados de Añatuya en Santiago del Estero. Nodo de desarrollo local e interacción macrorregional. Comechingonia, 18(1).

Taboada, C. (2017). Espacio, cultura material y procesos sociales tardíos en la llanura santiagueña. Modelo para pensar las poblaciones de la región. En Ventura, B. N., Ortiz, G., Cremonte, M. B., (Eds). Arqueología de la vertiente oriental Surandina. Interacción macro-regional, materialidades, economía y ritualidad. Ciudad Autónoma de Buenos Aires: Sociedad Argentina de Antropología. 237-266

Taboada, C., y Angiorama, C. (2010). Metales, textiles y cerámica. Tres líneas de análisis para pensar una vinculación entre los habitantes de la llanura santiagueña y el Tawantinsuyu. Memoria Americana, 18(2), 11-41.

Taboada, C., Angiorama, C., Leiton, D., y López Campeny, S. M. L. (2013). En la llanura y los valles... Relaciones entre poblaciones de tierras bajas santiagueñas y el estado inca: materialidades, elecciones y repercusiones. Intersecciones en Antropología, 14, 137-156.

Taboada, C., y Farberman, J. (2014). Asentamientos prehispánicos y pueblos de indios coloniales sobre el río Salado (Santiago del Estero, Argentina). Miradas dialogadas entre la arqueología y la historia. Revista de Arqueología Histórica Argentina y Latinoamericana, 8(1), 7-44.

Tamm, E., Kivisild, T., Reidla, M., Metspalu, M., Smith, D. G., Mulligan, C. J., ... Malhi, R. S. (2007). Beringian standstill and spread of Native American founders. PLoS ONE, 2(9), e829. doi:10.1371/journal. pone. 0000829

Tito, R. Y., Polo, S. I., y Lewis, C. M. Jr. (2012). Mitochondrial Genomes and Founder Effects within the Americas. Sin publicar. Secuencias disponibles en GenBank.

Togo, J. (2004). Arqueología Santiagueña: Estado actual del Conocimiento y Evaluación de un Sector de la Cuenca del Río Dulce. Tesis Doctoral inédita. Facultad de Ciencias Naturales y Museo, Universidad Nacional de La Plata, La Plata.

van Oven, M. (2015). PhyloTree Build 17: Growing the human mitochondrial DNA tree. Forensic Science International: Genetics Supplement Series, 5, 9-11. doi:10.1016/j.fsigss.2015.09.155 